\title{
Editorial: What is Ethical Care?
}

An individual's right to participate in decisions that concern him/her is the cornerstone of the legislation regarding care. But, as Sarah Shidler's article illustrates, this cornerstone must also take into account other rules that affect it. There are many different legal aspects, and harmonizing them is not always easy. In addition, the concept of the right to participate presupposes that the individual actually has the opportunity to do so. However, as Shidler clearly shows, the opportunity does not necessarily present itself in the case of an elderly person with a chronic disease, living in an institution. For such people, participation is often hindered by communication problems. Exercising one's right in decision making implies the ability to communicate. Communication is vital, it is an art to be cultivated.

Communication, however, is not always possible. Even when there is communication, it is never perfect. The law alone cannot guarantee that we do the right thing. Beyond the rules laid down by law, doing the right thing implies acting in an ethical manner. The question thus raised is "what is ethical care?"

I suggest the following definition: ethical care is care based on concern for the self, for others and for each individual. Being a good caregiver in the ethical sense means developing a way of acting that reflects these three concerns. By concern, we mean "preoccupation that holds our attention," as in "attention to detail". To pay attention to detail means to grant importance to detail. In the same way, to act with concern for self, for others and for each individual is to grant importance to self, to others and to each individual.

At first sight, the expression "concern for oneself" may be surprising, and indeed "concern for oneself" does sounds egocentric. But we should emphasize that "self' here is in opposition not to others or the individual, but to "me". Concern for self is not concern for oneself. The "self" refers to the reasonable side of ourselves as opposed to the "me" side, the aspect of ourselves dominated by our thoughtless desires. Concern for self indicates the human capacity to choose one thing over another, to act deliberately, to change the course of events or to set something in motion. Concern for self is fed by desire and reason, seeking to harmonize their mutual influence.

Showing concern for others may also be described as being supportive. Being supportive is a well-meaning spontaneity toward others. Being well-meaning to others implies that we recognize others as our fellow beings and equals. But this is not enough. Concern for others also implies reciprocity, reaching out to others. This reaching out must comprise both "giving" and "receiving," which must be reciprocated. At first, it is not 
obvious that a caregiving relationship can be reciprocal. After all, the sick person is the one receiving the care and the caregiver the one giving it.

How can there be reciprocity? Inspired by the writings of philosopher Paul Ricoeur, I would answer that it is in the suffering. The actual suffering of the person who suffers has a "giving" component. This "giving" does not come from the person's power to act but from his/her very weakness. This may seem surprising, but think about another phenomenon, that of the donation. Many sociological studies have shown that most people who do volunteer work feel that by giving their time, they receive more than they give. Organ donors often say they are receiving more than the recipient. The donor is transformed by the gift as much as the recipient. However unilateral a gift may appear, there is always something given in return. The example of the gift is a good illustration of the reciprocal dynamic found in concern for others. We are being supportive when we give and this "giving" is also "receiving".

Concern for each individual is different from concern for others. Here, "others" is used in the context of a personal relationship. "Each individual" refers to the other person in the context of a community, where community means a "structure for living together". The individual is the other in the capacity as a member of this structure. This structure for living together must be seen as a system for sharing, dividing up or distributing among its members. The system of dividing up takes into account sharing on an equal basis. Needless to say, when it comes to care, this does not mean giving each person an equal share of the care available, but giving each person an equal share of what he/she needs. The equal sharing referred to here is thus based each time on a relationship of equality between an individual and the need for care. This does not suggest that we must fill all needs. Limited resources may mean that the distribution is limited; but each time the distribution will respect the equal relationship between a person and his/her need as many times as there is someone with a need.

Providing care with concern for self, for others and for each individual is how I would answer the question "what is ethical care?". Acting in this way is simply acting according to excellence. But this excellence is merely a guiding image for which we strive. In each particular case, excellence is something vague. Faced with a specific case, what exactly is excellence? This question can be answered only through practical judgment. Practical judgment is a complex, multi-faceted process. The specific, unique feature of the case must be grasped. A degree of knowledge gained from experience in the broadest sense that is not limited to our own personal experience must have been acquired. The specific case must then be related to our experience, gauging, assessing and weighing it so that a choice can finally be made. The decision reached is the one deemed to be the best in terms of what is now the concrete form of excellence. Thus, this choice is based strictly on personal preference because it considers the lessons of experience. In using practical judgment, we must relate to experience, experience 
that comprises not only our own personal experience, but also, through dialogue, the experience of others. A person who has developed practical judgment is what Aristotle called "a prudent man," one who has developed as much his capacity to act with concern for the self, for others and for each individual as his capacity for practical judgment.

Ethical care thus implies that the agent has become a "prudent clinician". This prudent clinician is worthy of the name "practitioner". How can we become practitioners? In two ways. The first is by imitating a model. This is a well-known training method in medicine. It forms the basis of the training acquired when the student who has finished his/her medical studies becomes a "resident". "Residence" signals the transformation from physician to clinician. Interestingly enough, the word "patron" in French refers to both a clinical professor and a pattern used for cutting out a garment. A "patron" is a guide, a model; by following him/her, we ourselves become clinicians. The learning method is no different in ethics. Here we can say that the practitioner serves as a "patron," and by following him/her, we ourselves can become practitioners. The two examples obviously pose the same problems: not all "patrons" are true clinicians, and not all "patrons" are true practitioners. That is the inherent danger of this type of learning.

The second way of becoming a practitioner is through the decision-making process itself. As we practise, we take decisions and see that some are better than others. Over the years, our practical judgment skills improve. In this way, an evolutionary process takes place over time. The tougher the decisions, the more our practical judgment skills will be enhanced. It is more difficult for a dermatologist to become a practitioner (in the sense of prudent clinician) than it is for a cancer specialist, simply because the latter is more likely to be involved in tough decisions. In order to become a practitioner, we must agree to make difficult decisions. For this, we need will power, and also the will to examine our decisions critically after the event. These are the two ways of becoming a practitioner. It is not something than can be taught, but a process that transforms people gradually. 